\title{
The Application and Practice of Traditional Cultural Symbols in the Brand Design of "Nation Tide"
}

\author{
Yang Zhang ${ }^{1, *}$ \\ ${ }^{1}$ Academy of Fine Arts, Nanjing Xiaozhuang University, Nanjing, Jiangsu, China \\ *Corresponding author. Email: 2005053@njxzc.edu.cn
}

\begin{abstract}
In recent years, the "nation tide" of Chinese design has emerged. The main elements of the "nation tide" brand design come from traditional patterns, Chinese characters, colors, or traditional Chinese stories, traditional Chinese spirits and other traditional cultural symbols. The creation of the "nation tide" brands not only relies on the material element symbols to form the basic tone and external symbolic characteristics of the brand, but also requires the organic integration of the spirit and value of the excellent traditional culture, deeply thinking about traditional culture, and re-understanding and thinking about traditional cultural symbols from today's perspective, to let them produce new meanings in the designs.
\end{abstract}

Keywords: Traditional cultural symbols, "Nation tide" brands, Design.

\section{INTRODUCTION}

In recent years, the "nation tide" of the Chinese design industry has emerged. The "nation tide" is derived from the combination of the two Chinese words "nation" and "tide brand". It is the fashion brand that embodies the characteristics of Chinese culture and design. According to the released "Nation Tide Research Report" Tsinghua University's Institute of Cultural and Creative Development, taking 2018 as the first year of "nation tide", before the first year of nation tide, "nation tide" mostly refers to a specific brand in a narrow sense, that is, a trendy brand created by a local Chinese designer, which is a representative of a niche culture with distinctive characteristics; After entering the first year of nation tide, "nation tide" generally refers to a certain concept of consumption in a broad sense, that is, the popularity of domestic product groups and products with Chinese characteristics. [1] "Nation tide" brands usually have three key elements: high-quality products, Chinese symbols and trendy elements. As a local trend in China, a large number of Chinese cultural elements are incorporated into the design

*Project: 2021 Nanjing Xiaozhuang University Education and Teaching Research and Reform Key Project "The 'OBE' Concept of Visual Communication Design Professional Graphic Design Curriculum Teaching Research and Reform" phased results. theme. For Chinese people, Chinese culture is the crystallization of the spirit and wisdom retained by ancestors from generation to generation, and the root and soul of the Chinese nation. Chinese brands are beginning to pay attention to the excavation and inheritance of local culture, and the brand image of Made in China is gradually changing, and young consumers are beginning to become fascinated by "nation tide" products. The traditional Chinese culture in the "nation tide" brands not only satisfies the cultural pride of the Chinese people, but also attracts the attention of many foreigners. The main elements of the "nation tide" brand design come from traditional patterns, Chinese characters, colors or traditional Chinese stories, Chinese traditional spirit and other traditional cultural symbols. This is the source of the distinctive Chinese characteristics of the "nation tide" brands.

2. ANALYSIS OF THE CHARACTERISTICS OF TRADITIONAL CULTURAL SYMBOLS

\subsection{The Connotation of Traditional Cultural Symbols}

Human beings live in the world of symbols, and symbols are the medium of cultural transmission. 
Symbol is a certain conceptual symbol formed by the human brain's cognition and mapping of objective things. At the same time, it is an abstract spiritual carrier. Cultural symbols can then be regarded as a form of carrying traditional culture, which specially shows cultural connotation and artistic conception. Chinese traditional cultural symbols are based on the Chinese national cultural thoughts and integrate different ideological and cultural contents. On this basis, they inherit objectively existing cultural heritage, including traditional graphic symbols and traditional colors, with distinctive regional characteristics and spiritual connotations. These traditional visual symbols have become symbols of Chinese culture. Traditional visual symbols and traditional culture are inseparable. They reflect the Chinese people's outlook on life, values, ethics, customs, culture, and education, and embody the wisdom and philosophy of the Chinese nation. [2] The traditional cultural symbols in daily life include home decoration elements, such as patterns on doors, windows, tiles, etc., indoor furnishings and decorations with allegorical meaning, including auspicious symbols and patterns that express people's aspirations for a better life. For example, the door god of the Spring Festival, the dragon boat and rice dumplings of the Dragon Boat Festival, the rabbit and moon cakes of the Mid-Autumn Festival, etc., have fixed concepts and meanings in people's impressions. Traditional cultural symbols that have been passed down for thousands of years are in line with national aesthetic habits. Traditional cultural symbols with Chinese characteristics reflect the genes of traditional Chinese culture in terms of pattern expression, color, and connotation.

\subsection{Characteristics and Classification of Traditional Cultural Symbols}

Traditional cultural symbols can be divided into explicit symbols and invisible symbols. The application of explicit traditional cultural symbols in modern design can be divided into three aspects: traditional pattern symbols, traditional color symbols, and traditional material symbols. Through the extraction and reconstruction of these three symbols, a modern design with Chinese cultural connotations can be created. [3] China's abundant tangible and intangible cultural heritage is an extremely important source of designers' creative inspiration and creative materials, such as flying murals, weaving and dyeing, ceramics, silk, and New Year pictures, which collectively reflect the distinctive characteristics of Chinese culture.
Invisible symbols are inherently implicit and have a metaphorical effect. For example, Suzhou gardens can embody the traditional aesthetics of "the harmony between man and nature" and Zen design. The outstanding feature in the expression of traditional cultural concepts is to emphasize the harmony and unity of man and nature, the external natural phenomenon and the subject's emotional expression permeate and merge each other, and the matter and me, the subject and the object are perfectly integrated. The famous designer Mr. Jin Daiqiang has integrated his graphic design with traditional Chinese cultural symbols. Some traditional Chinese symbols such as pen, ink, paper, inkstone, ruler, compasses have been used in his poster design. Borrowing the philosophy of harmony between man and nature, and feelings of nature and humanity, he combined traditional Chinese aesthetics with design. The posters he designed are full of strong traditional artistic charm and contain Oriental philosophy. Starting from the traditional national culture of China, it is necessary to select representative and excellent external forms and internal spirits, and cleverly use them in the process of artistic design creation, so as to make the designers' own works convey a kind of unique cultural charm of China.

\section{ANALYSIS ON THE APPLICATION OF TRADITIONAL CULTURAL SYMBOLS IN THE BRAND DESIGN OF "NATION TIDE"}

\subsection{Analysis of Application Examples of Traditional Cultural Symbols}

Traditional culture influences people's lives imperceptibly, and provides a steady stream of inspiration and inspiration for the designs. More and more people attach importance to Chinese culture, forming a trend of vigorous development of the "nation tide". [4] Brands against the background of "nation tide" have more obvious symbolic characteristics, not only the external image directly reflects the traditional cultural elements such as image, color, line, form of composition, etc., but also a unique Chinese artistic aesthetic in the overall style, reflecting a consistent cultural identity and national emotions, and arousing people's spiritual resonance, which makes the brand's connotation deeper. Because of the common cultural identity, consumers are more likely to understand and accept the brand. 
The Oriental cosmetics brand Huaxizi was born in 2017. It is taken from Su Shi's famous saying "欲 把西湖比西子，淡妆浓抹总相宜 (I want to compare the West Lake as Xishi, who will always be beautiful whether in heavy or light makeups)". According to China's ancient tradition of women using flowers to nourish their faces, Huaxizi clearly defined its position, "Oriental make-up, and nourish makeup with flowers". Huaxizi's ingenuity inherits microcarving and embossing techniques, and integrates traditional Chinese elements such as dormer windows and folding screens. The brand has launched star products such as carved lipstick and Bainiao Chaofeng make-up tray, which integrates traditional cultural heritage into beauty products. The concentric lock lipstick launched on the Qixi Festival is a lipstick inspired by the "concentric lock". The concentric lock is said to be a treasure in the hands of Yue Lao, who is in charge of marriage. When a pair of lovers meet and know each other in the vast sea of people, they can send a concentric lock to each other, and they can be like a heart lock forever, in order to express the beautiful meaning of never separation. Concentric lock lipstick reproduces the "micro-relief craftsmanship", and engraves the pictures of the famous ancient romantic love story "Zhang Chang Thrushing" in the lipstick, showing the Oriental romantic love story in small square inches. In addition, in the Miao impression series products, the Miao silver craftsmanship is reproduced on the outer packaging of the products, combining the engraving craftsmanship with the oriental micro-carving technology, and the ancient and mysterious totem "Butterfly Mother" is selected on the pattern, which ingeniously integrates the Miao culture into the packaging of lipstick products. Through the selection and design of Miao traditional culture, Huaxizi has an unexpected advantage in product creativity. While disseminating traditional culture, traditional culture also gives Huaxizi products and brand culture a deeper connotation. For young consumers who are pursuing individualization, such a design has great appeal. It is the inheritance of traditional Chinese culture and makes Huaxizi's "Oriental Aesthetics" brand symbol deeply rooted in the hearts of the people.

As an old brand of domestic products, Jianlibao has a 35-year history of development. Recently, it has launched a new national style packaging, combining traditional Chinese auspicious patterns with fashion trends, using unique elements in traditional auspicious patterns, with a bright sense of color and refined graphics, which perfectly illustrate the oriental beauty with Chinese characteristics. The new packaging is divided into three series, namely Good Luck Koi, Lucky Panda and Made in China. Koi has always been synonymous with auspiciousness in the hearts of Chinese people. Two koi are grouped around to form a circle, which means peace and perfection, and symbolizes the Chinese people's yearning for a happy life. The Lucky Panda replaces the image of the God of Wealth in the traditional Chinese auspicious patterns. It combines the image of a national treasure and a traditional god to create new interest and is more acceptable to young people. Made in China is a relatively loud slogan today, and it has a strong sense of positive energy just like the auspicious patterns. The image of the Chinese dragon in the traditional auspicious pattern is integrated into the packaging graphics, and the development of Chinese aerospace and AI artificial intelligence is depicted. The collision of tradition and modernity gives people a novel feeling. In traditional culture, the symbol of imperial power, the dragon pattern, is updated here to reflect the beautiful meanings of auspiciousness, happiness, prosperity and so on, and express people's yearning for a better life. This is based on the designers' indepth understanding of traditional culture, and the integration of traditional culture into their product and brand design. It can be seen that the building of a successful brand not only relies on material element symbols to form the basic tone and external symbolic characteristics of the brand, but also requires the organic integration of excellent traditional cultural spirit and value.

\subsection{Research on the Design Method of Traditional Cultural Symbols in the Brand Design of "Nation Tide"}

From these examples, it can be seen that the use of traditional cultural symbols has been given a brand-new cultural connotation of the times, and its meaning is advancing with the times. In the context of cultural integration, the international stage, the integration of diverse ideas and various information viewpoints, the design and use of traditional cultural symbols have new meanings. For example, in the past, the dragon pattern symbolized imperial power and majesty, and the phoenix pattern represented dignity and sacredness. With the development of society, the dragon and phoenix patterns have been extended to auspicious, happiness, prosperity and other beautiful meanings that people love to see. Designers need to study the origin of symbols, and at the same time combine 
the historical process to transform Chinese traditional patterns in a reasonable and regulatory manner, so as to give new vitality to traditional cultural symbols. [5]

On the basis of respecting the original meaning and connotation of traditional cultural symbols, the designer combines the new applications of the current era to make breakthroughs in traditional culture and get rid of the shackles of tradition. Deconstruction and reconstruction of traditional cultural symbols should be used in modern design to open up the shackles of inherent thinking, break the original structure and combination of traditional cultural symbols, and innovate and combine to create a new concept that conforms to the development of the times. [6] Of course, this is based on understanding the connotation and meaning of traditional cultural symbols, and more importantly, understanding the artistic conception behind them, and making rational selections and deletions. It is necessary to use traditional Chinese symbolic styles and traditional colors to coordinate and unify Chinese culture with the brand tonality and overall design of the product. After fully understanding traditional culture and following market principles, by refining the forms of traditional elements and the spiritual concepts of local culture, the designers need to transform them into visual symbols, colors, structural forms, etc., and use them in brand design.

The "nation tide" brands, which take China's excellent traditional culture as their basic connotation, have gradually become symbols in their development, with distinct identifying characteristics. In the initial stage of brand establishment, in shaping the brand image, brand positioning and tonality, brand concept and other content, it is necessary to form a basic and unified visual recognition image of the brand, which is the symbolic basis that forms the basic identifying characteristics of the brand among consumers. [7]The reputation and overall image represented by the brand, as well as the trust and emotional dependence of consumers on the brand are the core values of the brand. Brand and product design should embody a unified cultural spirit connotation in the external image and concept. In the "nation tide" brand design, brand culture and Chinese culture are interdependent and progress together. From the perspective of shaping the overall design style of national and national brands, the in-depth integration of the Chinese national cultural spirit is the key to the formation of a deeper and broader influence of the brand, and the key to forming the common cultural gene of the national brand and shaping the Chinese style.

\section{CONCLUSION}

Now is an era of rapid development of symbol culture, and this era has gradually evolved into an era of symbol consumption. The country strongly emphasizes "cultural self-confidence". Consumers' demand for national cultural consumption is increasing rapidly. This strong desire for national cultural rejuvenation formed from top to bottom makes the spread of Chinese products and brands smoother. Only by deeply understanding the history and development of Chinese traditional culture, extracting meaningful traditional cultural symbols from it, reconstructing them, and integrating them into modern design to gain new vitality, can the designers make designs with traditional Chinese characteristics that are accepted by the public.

\section{AUTHORS' CONTRIBUTIONS} Zhang.

This paper is independently completed by Yang

\section{REFERENCES}

[1] Institute of Culture and Creativity, Tsinghua University. "Nation Tide Research Report" [R]. The 1st Boao Cultural and Creative Forum and Cultural and Creative Expo in 2019, 2019. (in Chinese)

[2] Qian Yajie, The Application of Traditional Cultural Symbols in Visual Image Design A Case Study of "Origrance" [D]. Master Degree Thesis of Southeast University, 2018. (in Chinese)

[3] Yang Jiazheng, Yang Jie, Analysis on the Application Practice of Chinese Traditional Cultural Symbols in Modern Design [J]. West Leather, 2021.2, 51-52. (in Chinese)

[4] Wang Chen, Research on Packaging Innovation of Old Brand from Perspective of the Nation Tide Culture [D]. Master Degree Thesis of Guangdong University of Technology, 2020. (in Chinese)

[5] Meng Dehua, Zhou Yangjing, Research on the Application of Traditional Patterns in "Nation Tide" Brand Design [J]. Art Education Research, 2020-08-15. (in Chinese) 
[6] Dong Chenglei, Inheritance and Innovation of Chinese Traditional Culture in Visual Communication Design [J]. JinGu Creative Literature, 2020-46, 49-50. (in Chinese)

[7] Wang Yuanyue, The Use of National Tide Cultural Symbols in Packaging Design [J]. Light Industry Science and Technology, 2020.2, 96-96+146. (in Chinese) 